Article

\title{
Density Dependence of Egg Recruitment and Moth Dispersal in Spruce Budworms
}

\author{
Jacques Régnière ${ }^{1, *}$ and Vincent G. Nealis ${ }^{2}$ \\ 1 Natural Resources Canada, Canadian Forest Service, 1055 PEPS Street, Quebec, QC G1V 4C7, Canada \\ 2 Natural Resources Canada, Canadian Forest Service, 506 Burnside Road West, Victoria, BC V8Z 1M5, Canada \\ * Correspondence: Jacques.Regniere@Canada.ca; Tel.: +1-418-648-5257
}

Received: 30 July 2019; Accepted: 15 August 2019; Published: 20 August 2019

\begin{abstract}
Egg recruitment quantifies the relative importance of realized fecundity and migration rates in the population dynamics of highly mobile insects. We develop here a formal context upon which to base the measurement and interpretation of egg recruitment in population dynamics of eastern and western spruce budworms, two geographically separated species that share a very similar ecology. Under most circumstances, per capita egg recruitment rates in these budworms are higher in low-density populations and lower in high-density populations, relative to the regional mean: Low-density populations are nearly always migration sinks for gravid moths, and dense populations nearly always sources. The slope of this relationship, measured on a log scale, is negatively correlated with migration rate, and ranges between 0 and -1 . The steeper the slope, the more marked net migration. Using our western spruce budworm observations, we found strong evidence of density-dependent emigration in budworms, so migration is not simply a random perturbation in the lagged, density-dependent stochastic process leading to budworm outbreaks. It is itself statistically and biologically density-dependent. Therefore, moth migration is a synchronizing factor and a spread mechanism that is essential to understanding the development and expansion of spruce budworm outbreaks at regional scales in the boreal forests of North America.
\end{abstract}

Keywords: spruce budworm; forest protection; early intervention strategy; egg recruitment; apparent fecundity; growth rate

\section{Introduction}

Recruitment of progeny is a fundamental ecological process determining inter-generation rates of change in the density of insect populations. When expressed per capita or as an apparent fecundity, recruitment is a survival rate. It can be combined with other stage-specific survival rates to connect the density of adults in one generation to that of eggs of the next generation across a time series of population measures. In many species, the adult is also a dispersal stage. If dispersing adults carry some or all of their progeny to new locations, then egg recruitment becomes a more complex phenomenon, particularly for spatial dynamics. Displacement of eggs resulting from dispersal of adult females can range from local redistribution of individuals within a habitat and gradual diffusion at the periphery, to long-range transport of winged, gravid females on air currents over hundreds of kms [1]. Even when it can be observed, the significance of dispersal may remain obscure as the source and destination of the dispersing adults, their survival en route, and reproductive status, are uncertain.

Forest insects display some of the most spectacular examples of eruptive population behavior, with periodic changes in population densities over several orders of magnitude. These outbreaks are often extensive as populations increase and decrease in apparent synchrony over vast areas [2-6]. Massive migrations of adult insects during outbreaks capture popular attention, but their importance in population dynamics is less obvious. In some cases, there is evidence migrations have initiated 
outbreaks de novo and even resulted in significant range expansions (e.g., [7]). However, more usually it is difficult to assess the net effect of dispersal on population patterns such as synchrony, as the practical problem of measuring dispersal is compounded by the close association between flight behavior and migration with meteorological and forest conditions at multiple spatio-temporal scales.

Such is the case with the spruce budworms, Choristoneura fumiferana (Clem.) and C. occidentalis Free., two of the most studied eruptive defoliators in the conifer forests of North America. In the eastern spruce budworm, synchrony of outbreaks over millions of hectares is documented in dendrochronologies $[6,8]$, defoliation surveys $[9,10]$ and direct measurement of populations [11,12]. Innovative field research has established the normative, detailed flight behavior of budworm moths, including gravid females, and their displacement under particular meteorological conditions, sometimes over great distances [1,13]. This research has enabled modeling flight behavior interfaced with high-resolution atmospheric models to simulate historic observations of spruce budworm dispersal over a large forested landscape [14]. Despite these insights, the extent to which outbreaks are initiated, as opposed to accelerated or supplemented, by immigration of egg-bearing moths, remains debatable $[15,16]$. Further, we are uncertain whether the periodic nature and large-scale spatial synchrony of spruce budworm outbreaks are dominated by common, intrinsic responses to widespread ecological conditions through the Moran effect $[4,16]$ or if dispersal plays a distinct role in these large-scale features of their population ecology [17]. This has significant implications for management of outbreaks. If dispersal and egg recruitment is an entirely stochastic process, then suppression of spruce budworm outbreaks can be implemented at the local, forest stand level with minimal regard for area-wide outbreak conditions. If, however, recruitment is dependent on area-wide densities and directional in the sense that these populations become synchronized, then increases in populations anywhere can trigger increases everywhere.

The per capita egg recruitment rate, or simply recruitment rate, was first defined as a survival rate for spruce budworm [18] and analyzed as the "female survival ratio" [19]. Royama [16] modified this to the "E/M ratio", the number of eggs recruited to the next generation per the number of moths in the previous generation. We prefer the more general term "apparent fecundity" for this measured per capita rate of recruitment. Apparent fecundity, in the absence of migration, is expected to be somewhat less than half the maximum lifetime fecundity of females, or $\approx 100$ eggs/moth, assuming a 1:1 sex ratio. Significant positive deviations from this expectation indicate net immigration of gravid moths, actually their eggs, and negative deviations indicate emigration. Royama 16] argued that apparent fecundity was density-independent and stochastic. His re-analysis of the Green River data concluded migration of gravid moths was a source of external noise that perturbs the details of the intrinsic temporal pattern during an outbreak cycle, but neither triggers nor causes spatial synchrony of outbreaks. In contrast, a theoretical argument was proposed that migration could be a strong source of population synchrony in spruce budworm outbreaks [17].

In this paper, we re-examine the measurement and interpretation of apparent fecundity in the study of spruce budworm population dynamics. We first describe the reproductive and dispersal ecology of the spruce budworm and how population estimates are made. We then provide a generalized theoretical framework to deduce the relationship between the recruitment rate and population density and identify how environmental factors obfuscate interpretation. We challenge our theoretical constructs with 14 previously unpublished, independent datasets obtained from literature or collected ourselves during outbreaks of spruce budworm. Finally, we analyze patterns of recruitment in different times and places and test the hypothesis that egg recruitment at the scale of outbreaks is a density-dependent process.

\section{Materials and Methods}

\subsection{The Budworm System}

Conifer-feeding budworms in the genus Choristoneura share common life-history adaptations and ecological relationships resulting in a periodic eruption of population densities over great expanses of 
their preferred host trees [20]. Adult moths are strong fliers and mated, gravid females can migrate actively several $\mathrm{km}$ and passively even further when transported on convective storm systems $[1,14,21]$. Dispersal may occur at any time in the reproductive cycle following mating and given suitable atmospheric conditions. However, fully-fecund, well-nourished adult females appear less capable of sustained flight, presumably as a result of wing loading, so some portion of their fecundity is realized at the natal location before migration [22,23]. On the other hand, food limitation resulting from severe defoliation reduces the size and fecundity of budworm moths with a commensurate positive effect of their propensity to disperse [24,25].

Dispersal is also a source of mortality, although this has never been measured in budworms. Redistribution within the normal flight range of individuals presents the least risk as spruce budworms are associated closely with very large areas of contiguous host plants and active flight allows expression of adaptive orientation behavior determining when and where to take off, land, and oviposit. Long-distance dispersal, however, is more hazardous as moths are passively transported on weather systems which ultimately may deposit them helplessly in hostile environments where they are lost from the system unless able to re-emigrate and take their chances again.

The data included in this analysis came from studies that measured egg and adult densities, allowing estimation of the per capita rate of egg recruitment or apparent fecundity. The conventional sample unit for spruce budworm life stages is a $45-\mathrm{cm}$ branch tip removed from the mid-crown of host trees [18]. Various expressions of density (per unit area, weight, shoot) can be used and because apparent fecundity is a ratio of densities in successive life stages, the density expression used is of no particular importance, provided both measurements are expressed in the same units.

Egg density is measured routinely by sampling branches after oviposition is complete but before significant loss of vacated egg masses from the foliage. Ideally, all eggs in the egg-mass sample should be counted because egg-mass size varies. More problematic is obtaining sufficient sample sizes at very low densities. If the sampled foliage does not harbor at least one egg-mass, apparent fecundity becomes null. Several sampling schemes were proposed to help determine the minimum sample sizes required [26,27]. This is a significant practical limitation because it is low-density populations where detection of immigration is most important.

Adult density must express the density of moths produced locally because it is the basis from which to assess deviations from the expected fecundity and net migration. The estimate of their density is based on counting pupal exuviae from which local adults have successfully emerged on the branch sample unit. Some have sampled throughout the adult emergence period to construct a daily, cumulative total of pupal exuviae from which they estimated successful eclosion of resident moths to counter the possibility that pupal cases disappeared quickly following adult emergence [11]. However, we did not observe a significant loss of pupal cases between peak adult emergence and the end of the egg hatch period two weeks later [28]. In our own work, we calculated adult density from late-season samples of larvae and pupae taken after $50 \%$ adult emergence and reduced those density estimates by recording mortality of remaining larvae and pupae in rearing $[28,29]$.

\subsection{Models}

We assume seasonal moth migration is a random process such that some proportion of the moths emerging from populations distributed over a large, heterogeneous landscape fly into the surface layer of air above the landscape, mix thoroughly, and land at random anywhere in the landscape. Thus, migrating moths can move short or long distances from source populations and the number of eggs carried by migrating moths and laid in a given location is independent of the density of the receiving population. Moreover, the number of migrants in the airspace in any one year is a regional constant resulting from the average density of populations in the region and weather conditions affecting flight behavior of moths in that year. The immigration rate, $I$, in eggs per unit foliage, can be represented by the function:

$$
I=\alpha \kappa F \beta \bar{M}
$$


where $\bar{M}$ is the average density of adults over the entire region, $F$ is potential or expected lifetime fecundity of a female moth, and $\kappa$ is the proportion of females ( 0.5 in spruce budworm) multiplied by survival from factors other than losses resulting directly from migration (e.g., predation) so that $0 \leq$ $\kappa \leq 1$. Realized fecundity is the product $\kappa F$. The proportion of fecundity carried away by migrants is $0 \leq \alpha \leq 1$, whether it results from the proportion of moths that emigrate, the proportion of their potential fecundity that moths carry with them when they emigrate, or some combination of the two. The proportion of migrating moths that survive during migration and lay eggs elsewhere is $0 \leq \beta \leq 1$.

The number of eggs $E$ laid in a given location or population is the sum of eggs deposited by immigrants I (Equation (1)) and those laid by resident moths either prior to take-off or by resident moths that do not emigrate at all:

$$
E=I+(1-\alpha) \kappa F M
$$

where $M$ is the density of locally-emerged moths.

The relationship between $E$ and $M$ is linear, with a non-zero intercept representing immigration to an empty population (when $M \rightarrow 0$ ) and a slope equal to the average number of eggs laid by the resident moths prior to take-off: $(1-\alpha) \kappa F$. In general, this slope is less than realized fecundity $\kappa F$ because $0 \leq \alpha \leq 1$. Apparent fecundity is given by:

$$
E / M=\frac{I}{M}+(1-\alpha) \kappa F
$$

Over a region where, by definition $\bar{M}$ is constant, the relationship between $E / M$ and $M$ decreases monotonically from an infinite intercept,

$$
\lim _{M \rightarrow 0}\left[\frac{I}{M}\right] \rightarrow \infty
$$

to an asymptotic minimum,

$$
\lim _{M \rightarrow \infty}\left[\frac{I}{M}+(1-\alpha) \kappa F\right]=(1-\alpha) \kappa F .
$$

The solid black lines in Figure 1 illustrate Equations (2) and (3). In this example, we set $\kappa F=0.5 \times$ $218 \mathrm{eggs} /$ adult (assuming a 50\% female sex ratio, no local mortality and a fecundity of $218 \mathrm{eggs} / \mathrm{female}$ ), $\alpha=0.5$ (50\% of moths take off, or moths lay $50 \%$ of their eggs before all leaving), and $\beta=0.5$ (50\% of migrating moths are lost during migration). The calculation of average moth density $\bar{M}$ assumes an even distribution across the density range in Figure 1.

In the extreme case of no migration so that all eggs are laid by surviving resident moths (i.e., $\alpha=0$ and therefore $I=0$ ), the relationship between $E$ and $M$ (Equation (2)) becomes $E=\kappa F M$, with intercept 0 and slope $\kappa F$ (dashed line in Figure 1a). Apparent fecundity (Equation (3)) is then a constant with respect to density and equal to realized fecundity, $\kappa F$. This results in a slope of 0 in the relationship between $\log (E / M)$ and $\log (M)$ (dashed line in Figure $1 b$ ). We define the other extreme as "panmixis", when all moths emigrate prior to laying any eggs $(\alpha=1)$. In this case, all eggs observed everywhere are laid by immigrants, and egg density becomes independent of local adult density (i.e., $E=I$, Equation (2)). Under these circumstances, apparent fecundity is inversely proportional to local adult density $((E=I / M)$, Equation (3), with 0 as its lower limit when $M \rightarrow \infty$. This extreme case gives a slope of -1 to the relationship between $\log (E / M)$ and $\log (M)$, and is illustrated by the dotted lines in Figure 1a,b. 
(a)

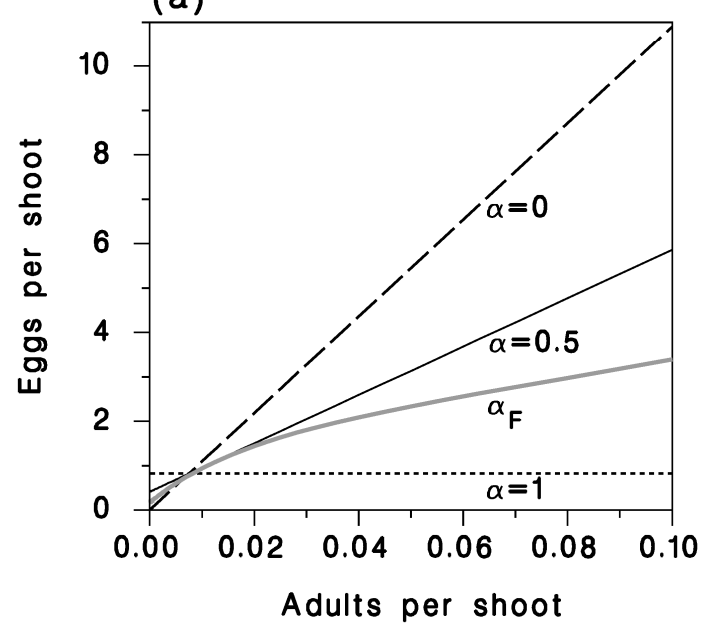

(b)

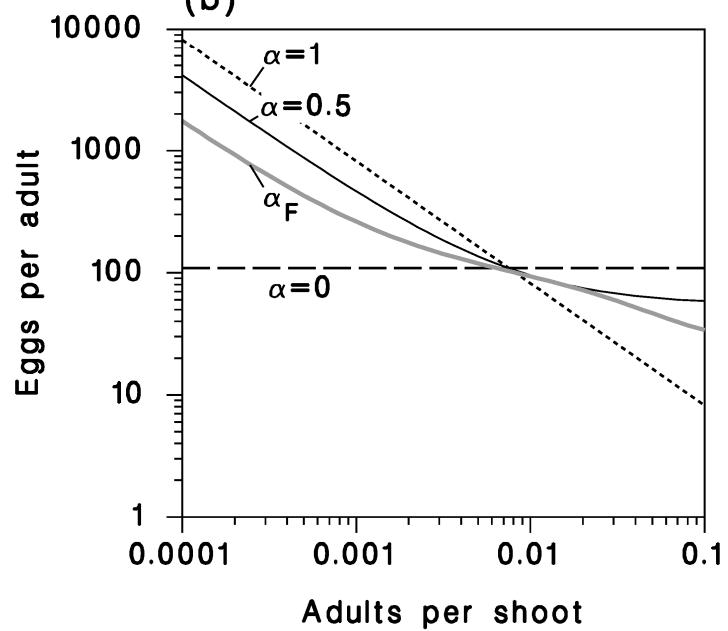

Figure 1. (a) Relationship between egg and adult density, illustrating Equations (2) (black lines) and (10) (grey line). (b) Relationship between apparent fecundity (eggs/adult) and adult density, illustrating Equations (3) (black lines) and (11) (grey line). Solid line: General case (where $\alpha=0.5$ ). Dashed line: No migration $(\alpha=0)$. Dotted line: Panmixis where all moth emigrate $(\alpha=1)$. Grey line: Density-dependent emigration (with $\alpha=0.5$ ). In all cases $\beta=0.5$.

Density-Dependent Emigration

Potential fecundity, $F$, in spruce budworms is reduced by food limitation associated with defoliation, $D$ [30]. From [31], we have:

$$
F_{D}=218-1.17 D
$$

We obtained data from [28] to fit an empirical relationship between defoliation $D(\%)$ and emerging adult density $M$ (Figure 2):

$$
D=\frac{100}{1+\exp (2.622-16.659 \sqrt{M})} .
$$

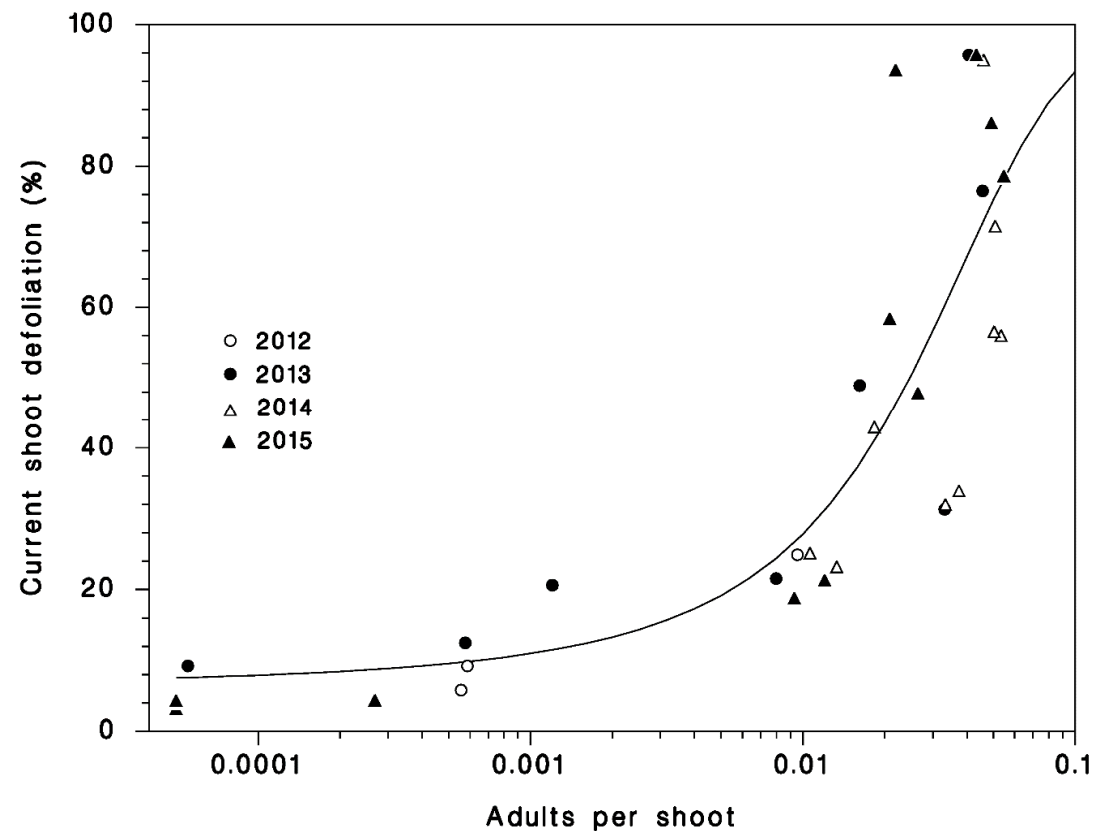

Figure 2. Relationship between adult density and defoliation of current year shoots on balsam fir foliage collected in the Lower St-Lawrence between 2012 and 2015. The line is Equation (7). 
Many authors contend budworm moths that are small as a result of food limitation have a greater propensity to fly and may even emigrate without first laying eggs $[13,24,25,32,33]$. On the other hand, large, fully-fed females may not be able to fly upon emergence and so do not migrate until they have laid at least a portion of their eggs at the natal site [23]. This suggests $\alpha$, the proportion of moths emigrating, could be a function of $F_{D}$ :

$$
\alpha_{F}=\alpha\left(\frac{218-F_{D}}{218-101}\right)
$$

that increases linearly from 0 when fecundity if 218 eggs/female ( $0 \%$ defoliation), to $\alpha$ when fecundity drops to $101 \mathrm{eggs} /$ female as occurs with $100 \%$ defoliation (Equation (8)).

Because the level of defoliation, and hence female weight, is a function of the density of feeding larvae, the emigration rate is now density-dependent, and so the immigration term (Equation (1)) must also be changed. Assuming a discrete number $n$ of populations in the area concerned, we can define the average density of eggs carried by emigrating moths as

$$
\bar{E}_{m}=\frac{1}{n} \sum_{i=1}^{n}\left(\alpha_{F} \kappa F_{D} M\right)_{i}
$$

and Equations (2) and (3) become

$$
E=\beta \bar{E}_{m}+\left(1-\alpha_{F}\right) \kappa F_{D} M
$$

and

$$
E / M=\frac{\beta \bar{E}_{m}}{M}+\left(1-\alpha_{F}\right) \kappa F_{D}
$$

This is illustrated by the grey lines in Figure 1 (for $\alpha=0.5, \beta=0.5$ and $\kappa=0.5$ ), assuming an even distribution of densities over the range in the figure. Density-dependent emigration makes the relationship between egg and local moth densities curvilinear (Figure 1a) and the resultant slope of the $\log (E / M)$ ratio vs. $\log (M)$ considerable less steep (Figure $1 b$ ).

\subsection{Datasets}

We obtained 13 datasets from spruce budworm and one from western spruce budworm (C. occidentalis Free.) populations collected between 1945 and 2015 in Canada. The first four datasets listed below were extracted from published literature and the remainder are presented here for the first time. Each study either provided estimates of apparent fecundity directly or included estimates of adult and egg densities from which apparent fecundity was calculated. Some data were collected during pesticide application trials, but we found no significant effect of treatments on apparent fecundity. All trials involved larvicides, and so affected the current density of the immature population only with no additional effect on adult behavior.

1. Green River 1945-1959. Four multiyear plots (G4, G5, K1, and K2) from the Green River Project, New Brunswick, Canada [34], digitized from (Figures 4 to 7 in [16]).

2. Five New Brunswick locations over four years (Table 2 in [35]). We transformed female density to total adults by assuming a 1:1 sex ratio and used an egg mass size of 18 eggs/mass [31].

3. Multiple-year population data from one location (Black Sturgeon Lake, Ontario) between 1983 and 1998 [36]. Apparent fecundity calculated from egg and adult density in the original dataset.

4. Twenty-two, single-year (1975) plots from an experiment to estimate immigration (Table 1 in [37]). In Area 1 (10 plots), insecticides were applied repeatedly during the season to reduce larval populations as low as possible. Area 2 (nine plots) was located near Area 1 and treated as per operational spruce budworm control. Area 3 (three plots) was not treated. 
5. Applications of insecticides in the Gatineau River Valley, Quebec on 12 plots (six controls, six treated) in a single year [38].

6. Applications of insecticides in north-central Ontario on nine treated and three control plots in a single year [39].

7. Applications of insecticides in the Gatineau River Valley, Quebec in 2000 [40].

8. Applications of pesticides in 12 plots plus four controls near Baie-Comeau, Quebec in 2008 [41].

9. Applications of pesticides in three treated and three control plots near Baie Comeau, Quebec in 2010 [42].

10. Lower St-Lawrence 2012-2015. Between six and 13 plots in four years (2012 to 2015) from the Lower St-Lawrence region, Quebec [28].

11. Western spruce budworm in British Columbia 1998-2015. Multiple years (18) and locations (three to 13) on untreated, outbreak populations of the western spruce budworm from Douglas-fir forests of in British Columbia covering an outbreak period from rise to decline [29].

\subsection{Data Analysis}

We compared two regression analysis methods to estimate the relationship between apparent fecundity and resident moth density. The first is a simple linear regression of observed egg density $E$ on the density of local moths $M$, Equation (2), and yields an intercept representing the immigration rate ( $I$ of Equation (1)) and a slope representing the realized fecundity of moths prior to take-off $(S=(1-$ $\alpha) \kappa F)$. Because the variance of spruce budworm population density estimates increases systematically with the mean [26], a log transformation and non-linear regression approach is used to estimate $I$ and $S$ :

$$
\log (E)=\log (I+S M)
$$

or alternatively:

$$
\log (E / M)=\log (I / M+S) .
$$

The second method is to regress $\log (E / M)$ on $\log (M)$ :

$$
\log (E / M)=a+b \log (M) .
$$

There is no simple mathematical relationship between $a$ and $b$ parameters in Equation (14) and the parameters $I$ and $S$ in Equation (13). While the latter parameters are readily interpretable biologically, the former, in particular, the slope $b$ of Equation (14), has an intuitively simple statistical interpretation that we discuss below. All 13 of the spruce budworm datasets were submitted to regression analysis using both models (12) and (14). For dataset 1 from the Green River Project [34], we compared apparent fecundities in $\mathrm{G}$ and $\mathrm{K}$ plots by oneway ANOVA on $\log (E / M)$.

The western spruce budworm dataset was used for two purposes. First, we obtained estimates of $\alpha$ and $\beta$ under both density-independent (Equation (3)) and density-dependent migration (Equation (11)) scenarios. We varied the two parameters systematically between 0 and 1 in steps of 0.01 and selected the pair of values that yielded the highest coefficient of determination $\left(R^{2}\right)$ between the observed apparent fecundity and the values calculated. Regional mean adult density $\bar{M}$ was calculated from all sites available in each year. Second, we investigated the relationship between both local and regional population densities with the value of apparent fecundity in the density-independent (Equation (3)) and density-dependent (Equation (11)) cases, using the parameter values obtained with the procedure above. The range of $M$ was varied systematically between $(-4.5,-2.5)$ and $(-2.5,-0.5)$ in steps of 0.05 (on $\log _{10}$ scale). The expected slope of $\log (E / M)$ vs. $\log (M)$ regressions ( $b$ in Equation (14)), was calculated for each density range. As a test of density dependence of the western spruce budworm's emigration rate, we compared the relationship between expected slope and average regional adult density with the annual estimates of slopes of the $\log (E / M)$ vs. $\log (M)$ regression obtained from the western spruce budworm dataset. 


\section{Results}

\subsection{Multi-Year Datasets}

We regressed egg density with respect to adult density (Equation (12)), and compared apparent fecundity calculated from Equations (13) and (14) with the observations from multiple-year datasets 1, 2, and 3 (Figure 3). In Green River (dataset 1), apparent fecundity was very different in G plots and K plot (Figure 3b). High densities in the K plots were accompanied by low apparent fecundity (39.5 \pm 10.9 and $26.4 \pm 7.6$ eggs/adult in $\mathrm{K} 1$ and $\mathrm{K} 2$, respectively), low densities in the G plots with very high apparent fecundity (212.2 \pm 60.8 and $229.7 \pm 73.1$ eggs/adult in G4 and G5, respectively). This order-of-magnitude difference in apparent fecundity was highly significant (ANOVA on $\log (E / M): F=6.8, \mathrm{~d} f=3.36, p=0.001$ ). This is strong evidence the relatively low-density $G$ plots were migration sinks, receiving more eggs than they exported during the course of the outbreak, while $\mathrm{K}$ plots were sources, exporting gravid moths from their outbreak populations. The high variability of this dataset relative to those that follow is due to its multiple-year nature and consequently the effects of annual variation in weather conditions affecting moth dispersal. The slope of the $\log (E / M)-\log (M)$ regression (Equation (14)) was $b=-0.41 \pm 0.07$, and the intercept was $a=1.93 \pm 0.07$. The corresponding immigration rate (from Equation (13)) was $I=17.54 \pm 0.01$ eggs $/ \mathrm{m}^{2}$, which translates to about 0.022 eggs/shoot (assuming 800 shoots $/ \mathrm{m}^{2}$ ). Realized local fecundity was $S=32.2 \pm 0.1$ eggs/adult.
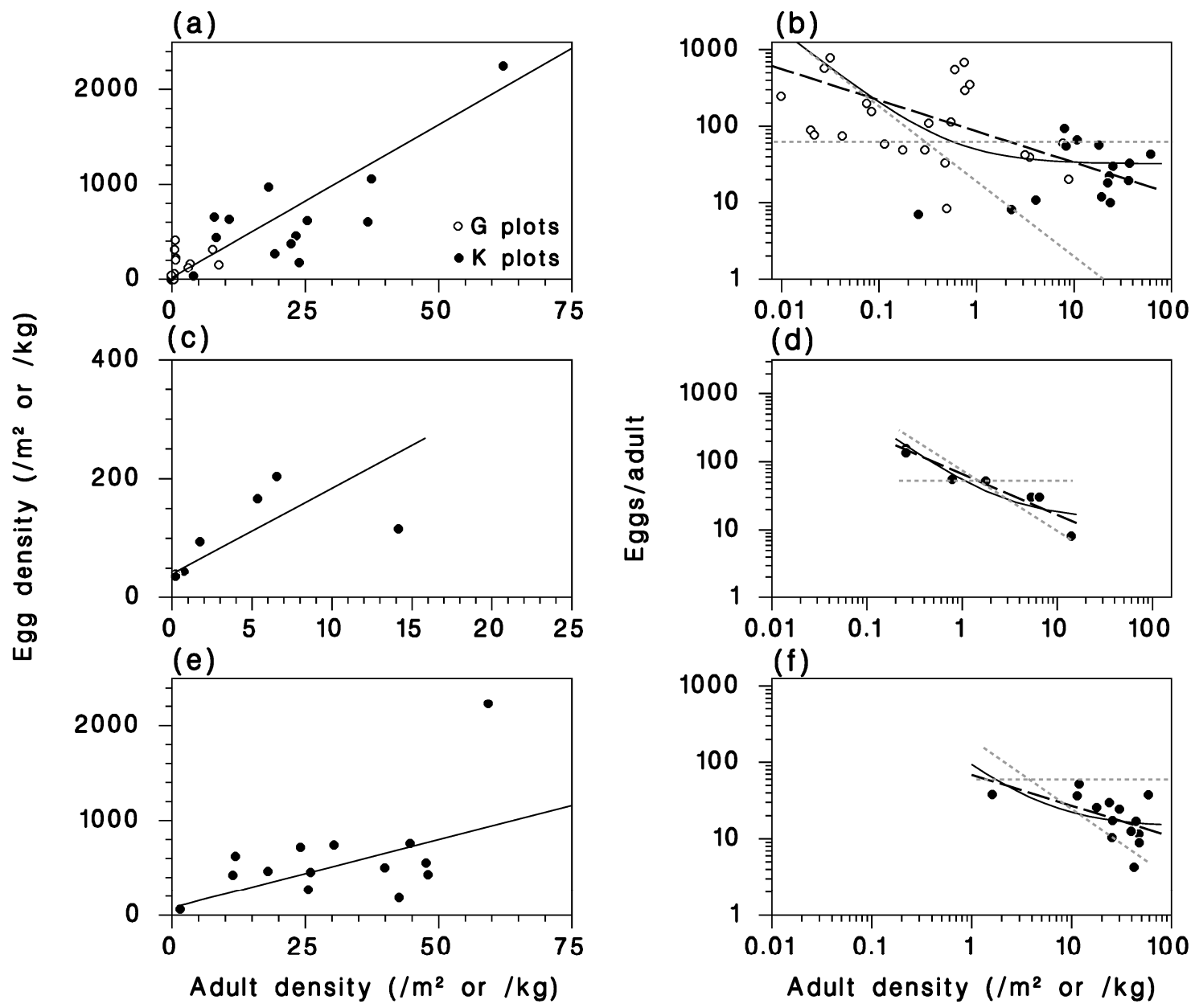

Figure 3. Three multiple-year datasets. Left column: Relationship between egg and adult density (lines are Equation (12)). Right column: Apparent fecundity (solid lines: Equation (13), dashed lines: Equation (14), horizontal dotted line: Expected realized fecundity (60s egg/moth), diagonal dotted lines: -1 slope, under panmixis $(\alpha=1)$. $(\mathbf{a}, \mathbf{b})$ Dataset 1 . $(\mathbf{c}, \mathbf{d})$ : dataset 2. $(\mathbf{e}, \mathbf{f})$ : dataset 3. 
Budworm densities recorded in dataset 2 were low and did not span as wide a range as those recorded in the other multiple-year datasets (1 and 3). Nonetheless, as in the other datasets, apparent fecundity was considerably higher in low-density plots than in plots with greater densities (Figure 3c,d). The slope of the $\log (E / M)-\log (M)$ regression (Equation (14)) was $b=-0.60 \pm 0.09$, and the intercept was $a=1.82 \pm 0.06$. The corresponding immigration rate (from Equation (13)) was $I=40.23 \pm 0.01$ eggs $/ \mathrm{m}^{2}$, which translates to about 0.05 eggs $/$ shoot (assuming 800 shoots $/ \mathrm{m}^{2}$ ). Realized local fecundity was $S=14.4 \pm 0.1$ eggs/adult. These parameter values suggest that migration rates to the low-density populations in dataset 2 were even greater than those observed in Green River's dataset 1 (Figure 3b).

Dataset 3 was collected over 13 years from a single site (Black Sturgeon Lake, Ontario) so annual variation in migration rates probably explains the wide scatter of apparent fecundity around the expected lines. Nonetheless, years with lower densities had consistently higher apparent fecundity and vice versa (Figure 3e,f). The slope of the $\log (E / M)-\log (M)$ regression (Equation (14)) was $b=-0.40 \pm 0.18$, and the intercept was $a=1.84 \pm 0.26$. The corresponding immigration rate (from Equation (13)) was $I=78.9 \pm 0.1$ eggs $/ \mathrm{kg}$, which translates to about 0.08 eggs $/$ shoot (assuming 1000 shoots $/ \mathrm{kg}$ ). Realized local fecundity was $S=14.4 \pm 0.1 \mathrm{eggs} /$ adult, identical to the realized fecundity in dataset 2 .

\subsection{Single-Year Datasets}

As with the multiple-year datasets, it is not possible to distinguish statistically between the fits of Equations (13) and (14) to each of the 10 single-year datasets (Figure 4). However, there is still a close relationship between the parameters of the two equations. The slope $S$ of Equation (13) is almost perfectly defined by the values of parameters $a$ and $b$ of Equation (14):

$$
\ln (S)=2.603 a-2.53 b\left(R^{2}=0.946,\right. \text { Figure 5a) }
$$

while its intercept $I$ is obtained, somewhat less precisely, from the slope $b$ and the regional-mean density $\bar{M}$ using:

$$
\ln (I)=-5.717-4.132 b+40.1 \bar{M}\left(R^{2}=0.854, \text { Figure } 5 b\right)
$$

Therefore, the analysis of apparent fecundity relationships with local density can be performed equally well with both regression approaches. However, the use of Equation (14) $(\log (E / M)-\log (M)$ regression) is simpler.

The immigration rate $I$ (in eggs per unit foliage), can be calculated from the regression parameters $a$ and $b$ of Equation (14) using Equation (16) (Figure 5a). The realized pre-emigration fecundity $S$ can be calculated from the slope $b$ of Equation (14) and the regional-mean adult density $\bar{M}$ with Equation (15). Using the $\log (E / M)-\log (M)$ regression (Equation (14)) also has the advantage of giving a direct comparison with the two extreme cases (no migration and panmixis). The closer to -1 the slope is, the more migration has occurred (value of $\alpha$ closer to 1).

On average over our 10 single-year datasets, $a=0.369, b=-0.158$ and $\bar{M}=0.027$ adults/shoot. These correspond to $I=0.126 \mathrm{eggs} / \mathrm{shoot}$ and $S=14.25 \mathrm{eggs} / \mathrm{adult}$. Two of these datasets have slopes $b$ very near -1 (Figure $4 \mathrm{a}, \mathrm{h}$ ) suggesting extensive emigration rates near the extreme case of panmixis when all moths redistribute among all populations $(\alpha=1)$. Three others are close to the opposite case with the apparent absence of emigration $(\alpha=0)$, with slope $b$ near 0 (Figure $4 \mathrm{~d}, \mathrm{e}, \mathrm{g}$ ). The rest (Figure $4 \mathrm{~b}-\mathrm{d}, \mathrm{f}$ ) are in the intermediate range where $b \approx-0.5$.

In general, one can expect apparent fecundity to be high in regions undergoing an outbreak (high $\bar{M}$ ) in years when the emigration rate is high $(\alpha \rightarrow 1)$. Under such circumstances, the apparent fecundity in sink populations, where local densities are lower than average, become much higher than expected fecundity. Conversely, apparent fecundity in sources, where densities are above the regional mean, are lower than expected fecundity. The result is homogenization of populations in a highly density-dependent manner with lower-density populations in any one year experiencing greater per capita recruitment rates as a result of net immigration of gravid moths. These moths are leaving high-density populations which then have low per capita egg recruitment rates. 

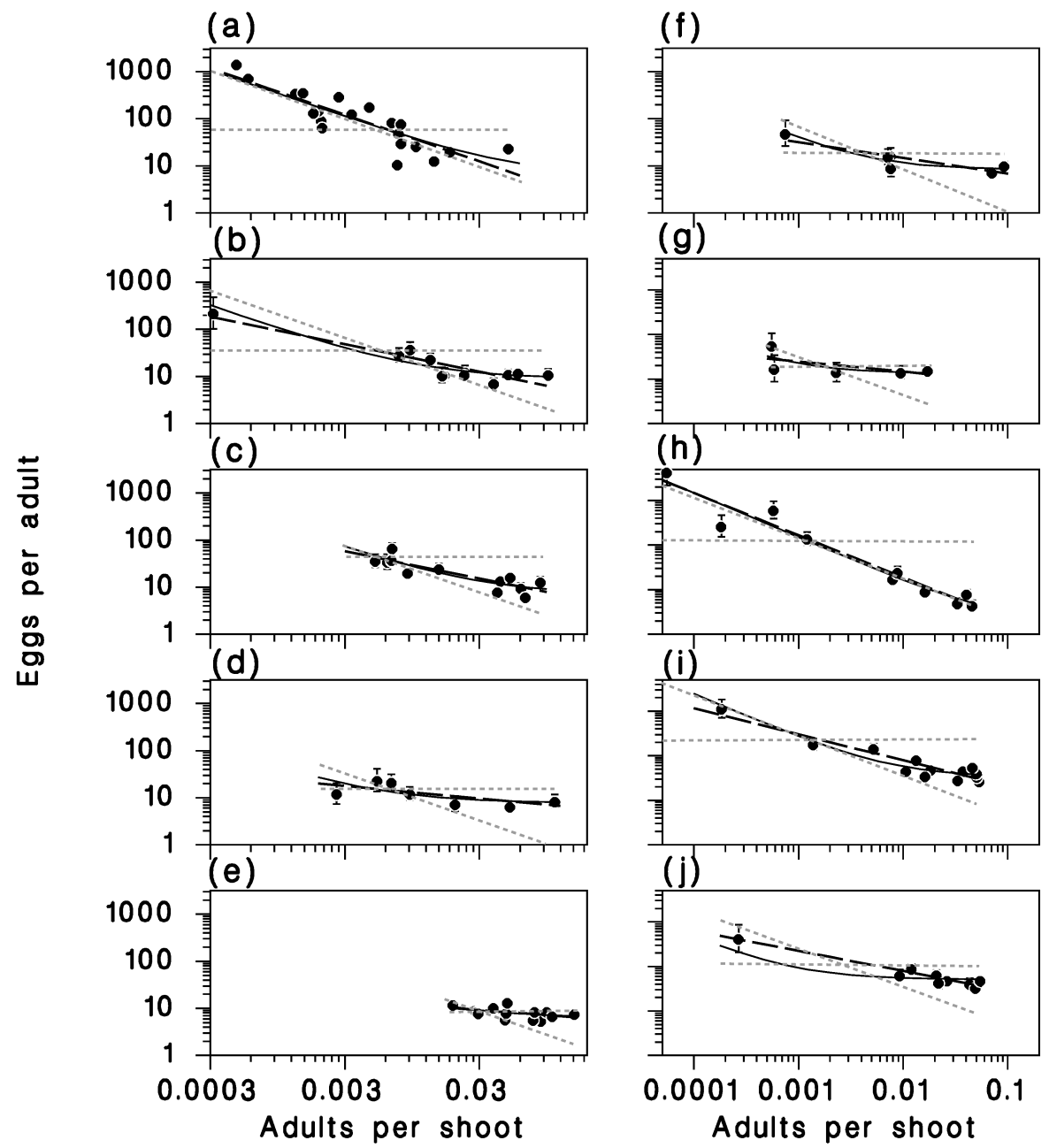

Figure 4. Apparent fecundity in relation to local adult density in ten single-year, multiple-site datasets. Solid lines: Equation (13), dashed lines: Equation (14), horizontal dotted line: Average apparent fecundity, diagonal dotted lines: -1 slope under panmixis $\alpha=1$ ). (a) Dataset 4 , (b) dataset 5, (c) dataset 6, (d) dataset 7, (e) dataset 8, (f) dataset 9, (g-j) Lower St-Lawrence datasets 10 to 13.
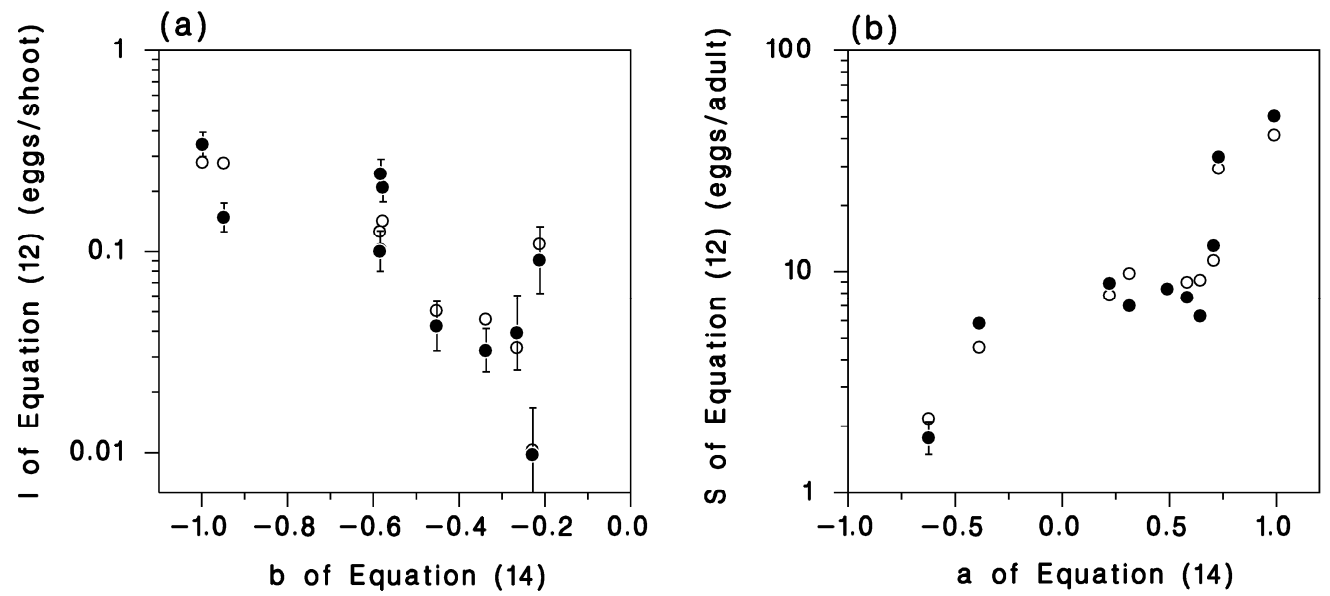

Figure 5. Relationships between parameters of Equations (13) and (14). (a) I, intercept of Equation (13) (immigration rate in eggs/shoot) is explained mostly by $b$, slope of Equation (14), the rest by $\bar{M}$, the regional-mean density, predicted values calculated with Equation (16). (b) $S$, slope of Equation (13) (realized fecundity in eggs/adult) is explained mostly by $a$, intercept of Equation (14), the rest by $b$, its slope, predicted values calculated with Equation (15). Vertical bars are SE of the parameter. 


\subsection{Western Spruce Budworm}

The best fit in this long-term, multi-location dataset was obtained with Equation (3) (density-independent fecundity and emigration a random process) using parameter values $\alpha=$ $0.59, \beta=0.27$, and constant fecundity $F=218$ eggs/female. The resulting $R^{2}$ between observed and expected apparent fecundity (on regular scale) is 0.32. Using Equation (11) (density-dependent fecundity and emigration rate) the best fit was obtained with $\alpha=1, \beta=0.26$ (on regular scale, $R^{2}=$ 0.40 ), a significant improvement in goodness of fit (Mallows $C_{P}=1.0$ with Equation (11) compared to $C_{P}=18.2$ with Equation (3)).

When the range in adult density is varied systematically from low to high using the parameter estimates obtained above, the difference between density-independent and density-dependent migration becomes evident. If fecundity and emigration rates are independent of density (Equation (3)), the slope of the $\log (E / M)-\log (M)$ regression does not vary with average regional density but remains constant at $b=-0.45$. However, when $F$ and $\alpha$ are density-dependent (Equation (11)), the slope of the density relationship decreases from $b=-0.18$ when regional mean density is low, to $\mathrm{b}=-1$ when regional density is highest. The western spruce budworm dataset confirms this predicted pattern (Figure 6). Observed annual fluctuations in the slope of the $\log (E / M)-\log (M)$ regression are negatively correlated with fluctuations of regional mean density (Figure 6a). This negative association reflects the prediction (solid grey line in Figure 6b). This constitutes strong evidence that emigration is density-dependent in spruce budworms.
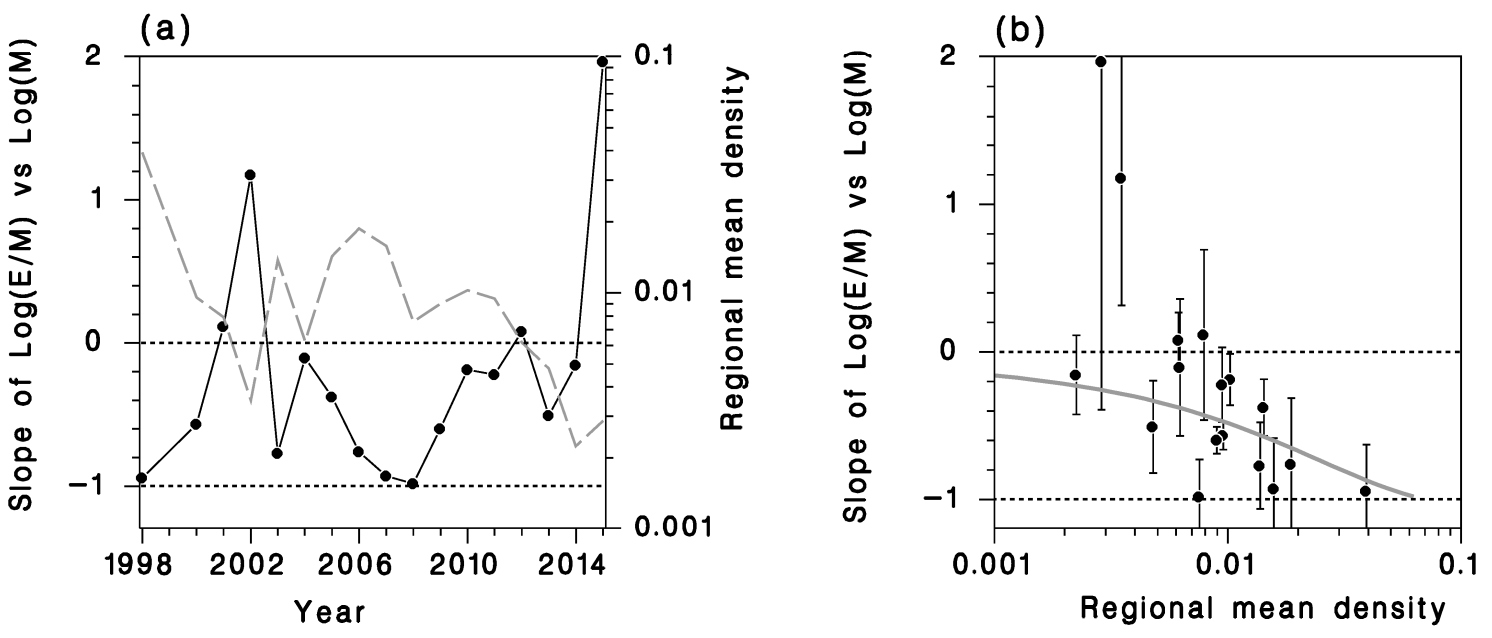

Figure 6. (a) Annual variation of the slope of the $\log (E / M)-\log (M)$ regression (Equation (14), solid line and closed symbols) and of regional-mean adult density (dashed line) in southcentral British Columbia from 1998 to 2015. (b) Relationship between the slope of the $\log (E / M)-\log (M)$ relationship and regional mean adult density. Vertical bars are SE of the parameter, solid grey line it the relationship expected from density-dependent emigration described by Equation (11) with $\alpha=1, \beta=0.26$ and $\kappa=0.5$, horizontal lines are two extreme cases: No migration $(\alpha=0)$ and panmixis $(\alpha=1)$.

\section{Discussion}

Dispersal of winged, adult insects is one of the most important yet enigmatic aspects of insect population ecology. Their capacity to disperse and the fact that they do is obvious to the most casual observer. Massive swarms of forest insects, including spruce budworms, near light sources are impressive, newsworthy events. Anecdotal accounts of outbreaks following such in-flights of moths [43] have been confirmed by direct observation [1]. However, these could be exceptional circumstances, significant at the local scale but transient and inconsequential at the regional scale. For example, observed flights of moths from New Brunswick to Newfoundland in Atlantic Canada in the 1980s resulted in damaging outbreaks which lasted only a few years while the source outbreak on the mainland continued for several more years [21]. Our understanding of the ecological conditions 
determining if, when, and where spruce budworms fly, are relatively well known (e.g., [44-46]) but the application of this knowledge to the analysis of population patterns is challenging and has only been accomplished recently [47]. As extensive, annual records of defoliation of outbreaks became available, the research approach on dispersal shifted to empirical, geo-statistical techniques to infer patterns of direction and rate of 'spread' in defoliation that might reveal the ecological structure of moth dispersal $[4,10,48]$. Skeptical of these empirical estimates, theoretical models simplified the difficulty by assigning a random effect with respect to population rates of change $[17,49,50]$.

None of this led to a consensus on the critical question regarding dispersal in spruce budworms, namely, is the large-scale, eruptive dynamics of spruce budworm populations the result of net migration of gravid moths from sources to sinks or are these migrants simply supplementing a general, regional increase population density driven by other large-scale factors such as weather or the availability of susceptible forests? This question has a direct bearing on management strategies. If outbreaks spread from epicenters by moth dispersal, then aggressive suppression of early-rising populations to reduce migrants, irrespective of their location, should be effective [51]. On the other hand, if populations are on the rise everywhere and apparent epicenters are just the first to be detected [17], pest managers have little choice other than to wait until high-valued stands are damaged unacceptably before intervening.

The field data analyzed here provide testable evidence that dispersal of gravid spruce budworm moths is fundamental to population dynamics as it can play a significant role in the initiation of outbreaks and influence the characteristics of outbreak patterns over the entire range of regional outbreaks. We found a consistent, inverse relationship between the rate of egg recruitment and the density of the moth population in independent data from several areas in different time periods and a wide range of local densities. This constitutes statistical density dependence. Spruce budworm populations are a patchwork of sources and sinks which tend to homogenize as mean regional densities increase. The process is not stochastic, high-density populations are sources that export gravid moths to low-density sinks. Losses during migration tend to reduce overall realized fecundity but this mortality may be insignificant at the regional level or more related to weather conditions during flight than population densities. Consequently, population growth rates in low-density populations tend to increase and the lower, realized fecundity in high-density populations may be compensated by reduced mortality among progeny $[11,16,29,36]$. Further, we demonstrate that biologically density-dependent emigration is a plausible explanation of why the slope of the $\log (E / M)-\log (M)$ relationship decreases (becomes closer to -1 ) as regional mean density increases. This systematic change can only be observed in the same regional context over several years while population density changes. It cannot be adequately tested from samples taken in different regions although the scale of moth movement that defines the ecological region of interest is very large (100 to $1000 \mathrm{~s}$ of $\left.\mathrm{km}^{2}\right)$.

\section{Conclusions}

We conclude that migration is central in spruce budworm population dynamics as it is density-dependent in both the statistical and biological sense and not simply a source of vertical perturbation in a random process. It plays a role in synchrony and spread of outbreaks because homogenization is inevitable. Density-dependent dispersal is a sufficiently powerful process to offset local declines in generation survival providing there is a source of emigrants [29]. This phenomenon has been evident to forest pest managers disappointed by re-invasion of forests where pesticide treatments have reduced budworm population densities [37] or populations have recovered immediately following a collapse [31]. It also explains the collapse of outbreaks over a broad region once most populations are experiencing declines in survival such that potential sources are less frequent or more remote [29].

The ubiquitous statistical density dependence of spruce budworm egg recruitment at the regional scale implies that moth dispersal tends to homogenize population. Low-density populations tend to have high growth rates, high-density populations low growth rates. In addition, biological density-dependence implies that as a regional outbreak develops and average density increases, the slope of the statistical density dependence of egg recruitment (and hence population growth rates) 
becomes steeper (closer to -1 ). Fluctuations of apparent fecundity have been viewed as a source of stochastic (random) perturbation on an autoregressive, non-linear stochastic process through the Moran effect [52,53]. Many authors have discussed the difficulty of synchronizing metapopulations fluctuations by a Moran effect when inherent cycling frequencies are spatially heterogeneous [54-56], which should be the case in insects like spruce budworms that are distributed over very large and diverse landmasses. However, statistically or biologically density-dependent dispersal introduces additional complexity to its effect on metapopulation synchrony and stability $[57,58]$ that are beyond the aim of this paper and merit thorough investigation.

However, density-dependent apparent fecundity and migration rate may be the strongest arguments in support of an early intervention strategy against spruce budworm outbreaks. Such a strategy, applied in an area-wide fashion, involves detecting and suppressing any high-density populations to prevent their becoming sources. When this is done early, while the regional mean budworm population density is low and survival rates are also low [28], redistribution of eggs through moth dispersal is minimized and it is possible that an outbreak can be prevented, or at least delayed.

Author Contributions: Conceptualization, formal analysis, writing and reviewing, J.R.; data contribution, writing, reviewing, V.G.N.

Funding: The original data and research was funded by members of SERG-international, including SOPFIM, Forest Protection Limited, the governments of Newfoundland, New Brunswick, Quebec, Ontario, Manitoba and Saskatchewan, as well as the USDA Forest Service.

Acknowledgments: We acknowledge Alain Dupont (SOPFIM), Ed Kettela and Kees van Frankenhuyzen for allowing the use of their data. We thank Ariane Béchard for her help in the conduct of the Lower St-Lawrence study and Rod Turnquist for assistance with western spruce budworm.

Conflicts of Interest: The authors declare conflict of interest.

\section{References}

1. Greenbank, D.O.; Schaefer, G.W.; Rainey, R.C. Spruce budworm (Lepidoptera: Tortricidae) moth flight and dispersal: New understanding from canopy observations, radar and aircraft. Mem. Entomol. Soc. Can. 1980, 110. [CrossRef]

2. Hanski, I.; Woiwod, I.P. Spatial synchrony in the dynamics of moth and aphid populations. J. Anim. Ecol. 1993, 62, 656-668. [CrossRef]

3. Myers, J.H. Synchrony in outbreaks of forest lepidoptera: A possible example of the Moran effect. Ecology 1998, 79, 1111-1117. [CrossRef]

4. Williams, D.W.; Liebhold, A.M. Spatial synchrony of spruce budworm outbreaks in eastern North America. Ecology 2000, 81, 2753-2766. [CrossRef]

5. Peltonen, M.; Liebhold, A.M.; Bjornstad, O.N.; Williams, D.A. Spatial synchrony in forest insect outbreaks: Roles of regional stochasticity and dispersal. Ecology 2002, 83, 3120-3129. [CrossRef]

6. Jardon, Y.; Morin, H.; Dutilleul, P. Périodicité et synchronisme des épidémies de la tordeuse des bourgeons de l'épinette au Québec. Can. J. For. Res. 2003, 33, 1947-1961. [CrossRef]

7. Safranyik, L.; Carroll, A.L.; Régnière, J.; Langor, D.W.; Riel, W.G.; Shore, T.L.; Peter, B.; Cooke, B.J.; Nealis, V.G.; Taylor, S.W. Potential for range expansion of mountain pine beetle into the boreal forest of North America. Can. Entomol. 2010, 142, 415-442. [CrossRef]

8. Simard, I.; Morin, H.; Lavoie, C.A. Millenial-scale reconstruction of spruce budworm abundance in Saguenay, Québec, Canada. Holocene 2006, 16, 31-37. [CrossRef]

9. Hardy, Y.J.; Mainville, M.; Schmidt, D.M. Spruce Budworms Handbook: An Atlas of Spruce Budworm Defoliation in Eastern North America, 1938-1980; USDA Forest Service: Beltsville, MD, USA, 1986; p. 52.

10. Bouchard, M.; Auger, I. Influence of environmental factors and spatio-temporal covariates during the initial development of a spruce budworm outbreak. Lands. Ecol. 2014, 29, 111-126. [CrossRef]

11. Royama, T.; Eveleigh, E.S.; Miron, J.R.B.; Pollock, S.J.; McCarthy, P.C.; McDougall, G.A.; Lucarotti, C.J. Mechanisms underlying spruce budworm outbreak processes as elucidated by a 14-year study in New Brunswick, Canada. Ecol. Monogr. 2017, 87, 600-631. [CrossRef] 
12. Bouchard, M.; Régnière, J.; Therrien, P. Bottom-up factors contribute to large-scale synchrony in spruce budworm populations. Can. J. For. Res. 2018, 48, 277-284. [CrossRef]

13. Greenbank, D.O. The role of climate and dispersal in the initiation of outbreaks of the spruce budworm in New Brunswick: II. The role of dispersal. Can. J. Zool. 1957, 35, 385-403. [CrossRef]

14. Sturtevant, B.R.; Achtemeier, G.L.; Charney, J.J.; Anderson, D.P.; Cooke, B.J.; Townsend, P.A. Long-distance dispersal of spruce budworm (Choristoneura fumiferana Clemens) in Minnesota (USA) and Ontario (Canada) via the atmospheric pathway. Agric. For. Meteorol. 2013, 168, 186-200. [CrossRef]

15. Royama, T. Effect of adult dispersal on the dynamics of local populations of an insect species: a theoretical investigation. In Dispersal of Forest Insects: Evaluation, Theory and Management Implications; Berryman, A.A., Safranyik, L., Eds.; Wash. State Univ.: Pullman, WA, USA, 1979; pp. 79-93.

16. Royama, T. Population dynamics of the spruce budworm Choristoneura fumiferana. Ecol. Monogr. 1984, 54, 429-462. [CrossRef]

17. Régnière, J.; Lysyk, T.J. Population dynamics of the spruce budworm, Choristoneura fumiferana. In Forest Insects Pests in Canada; Armstrong, J.A., Ives, W.G.H., Eds.; Natural Resources Canada, Canadian Forest Service: Ottawa, ON, Canada, 1995; pp. 95-105.

18. Morris, R.F.; Miller, C.A. The development of life tables for the spruce budworm. Can. J. Zool. 1954, 32, 283-301. [CrossRef]

19. Greenbank, D.O. The analysis of moth survival and dispersal in the unsprayed area. In the Dynamics of Epidemic Spruce Budworm Population; Morris, R.F., Ed.; The Memoirs of the Entomological Society of Canada: Ottawa, ON, Canada, 1963; pp. 87-99.

20. Nealis, V.G. Comparative ecology of conifer-feeding spruce budworms (Lepidoptera: Tortricidae). Can. Entomol. 2016, 148 (Suppl. 1), S33-S57. [CrossRef]

21. Dobesberger, E.J.; Lim, K.P.; Raske, A.G. Spruce budworm (Lepidoptera: Tortricidae) moth flight from New Brunswick to Newfoundland. Can. Entomol. 1983, 115, 1641-1645. [CrossRef]

22. Wellington, W.G.; Henson, W.R. Note on the effects of physical factors on the spruce budworm, Choristoneura fumiferana (Clem.). Can. Entomol. 1947, 79, 168-170. [CrossRef]

23. Rhainds, M.; Kettela, E.G. Oviposition threshold for flight in an inter-reproductive migrant moth. J. Ins. Behav. 2013, 26, 850-859. [CrossRef]

24. Blais, J.R. Effects of the destruction of the current year's foliage of balsam fir on the fecundity and habits of flight of the spruce budworm. Can. Entomol. 1953, 85, 446-448. [CrossRef]

25. Van Hezewijk, B.; Wertman, D.; Stewart, D.; Beliveau, C.; Cusson, M. Environmental and genetic influences on the dispersal propensity of spruce budworm (Choristoneura fumiferana). Agric. For. Entomol. 2018, 20, 433-441. [CrossRef]

26. Régnière, J.; Sanders, C.J. Optimal sample size for the estimation of spruce budworm (Lepidoptera: Tortricidae) populations on balsam fir and white spruce. Can. Entomol. 1983, 115, 1621-1626. [CrossRef]

27. Lysyk, T.J.; Sanders, C.J. A method for sampling endemic populations of spruce budworm (Lepidoptera: Tortricidae) based on proportion of empty sample units. Can. For. Serv. Info. Rep. 1987, O-X-382, 17.

28. Régnière, J.; Cooke, B.J.; Béchard, A.; Dupont, A.; Therrien, P. Dynamics and management of rising outbreak spruce budworm populations. Forests 2019. under review.

29. Nealis, V.G.; Régnière, J. Ecology of outbreak populations of the western spruce budworm. Ecol. Monogr. 2019. under review.

30. Miller, C.A. The analysis of fecundity proportion in the unsprayed area. In the Dynamics of Epidemic Spruce Budworm Population; Morris, R.F., Ed.; The Memoirs of the Entomological Society of Canada: Ottawa, ON, Canada, 1963; pp. 75-87.

31. Nealis, V.G.; Régnière, J. Fecundity and recruitment of eggs during outbreaks of the spruce budworm. Can. Entomol. 2004, 136, 591-604. [CrossRef]

32. Wellington, W.G. The light reactions of the spruce budworm, Choristoneura fumiferana Clemens (Lepidoptera: Tortricidae). Can. Entomol. 1948, 80, 56-82. [CrossRef]

33. Henson, W.R. The Means of Dispersal of the Spruce Budworm. Ph.D. Thesis, Yale University, New Haven, CT, USA, 1950.

34. Morris, R.F. The dynamics of epidemic spruce budworm population. Mem. Entomol. Soc. Can. 1963, 31, 30-32. [CrossRef] 
35. Miller, C.A.; Greenbank, D.O.; Kettela, E.G. Possible use of canopy light traps in predicting spruce budworm egg-mass counts. Can. For. Serv. Bi-Mon. Res. Notes 1979, 35, 29-30.

36. Régnière, J.; Nealis, V. Ecological mechanisms of population change during outbreaks of the spruce budworm. Ecol. Entomol. 2007, 32, 461-477. [CrossRef]

37. Miller, C.A.; Greenbank, D.O.; Kettela, E.G. Estimated egg deposition by invading spruce budworm moths (Lepidoptera: Tortricidae). Can. Entomol. 1978, 110, 609-615. [CrossRef]

38. Régnière, J. Results of the 1999 Early Intervention Project. SERG-International Annual Workshop Proceedings. Available online: www.serginternational.org (accessed on 16 August 2019).

39. Régnière, J. Early intervention against SBW: Results of the 1999-2001 preliminary trials on Mimic and Bt. SERG-International Annual Workshop Proceedings 2001. Available online: www.serginternational.org (accessed on 16 August 2019).

40. Régnière, J.; Kettela, E.G.; van Frankenhuyzen, K. SERG Project 1999/05: Early Intervention against Spruce Budworm: High dosage Foray 96B in Ontario in 2000. SERG-International Annual Workshop Proceedings 2001. Available online: www.serginternational.org (accessed on 16 August 2019).

41. Trudel, R.; Dupont, A.; Bélanger, A. Experimental Pheromone Applications Using Disrupt Micro-Flakes SBW $^{\circledR}$ for the Control of the Spruce Budworm Populations: Quebec Mating Disruption Trials 2008. SERG-International Annual Workshop Proceedings 2011. Available online: www.serginternational.org (accessed on 16 August 2019).

42. Régnière, J.; Delisle, J.; Pureswaran, D.; Trudel, R. Mate-finding Allee effect in spruce budworm population dynamics. Entomol. Exp. Appl. 2012, 146, 112-122. [CrossRef]

43. Craighead, F.C. Studies on the spruce budworm [Cacoecia fumiferana Clem.]. Part II. General bionomics and possibilities for prevention and control. Can. Dep. Agric. Tech. Bull. 1924, 37, $28-57$.

44. Boulanger, Y.; Fabry, F.; Kilambi, A.; Pureswaran, D.; Sturtevant, B.R.; Saint-Amant, R. The use of weather surveillance radar and high-resolution three dimensional weather data to monitor a spruce budworm mass exodus flight. Agric. For. Meteorol. 2017, 234-235, 127-135. [CrossRef]

45. Régnière, J.; Delisle, J.; Sturtevant, B.R.; Garcia, M.; Saint-Amant, R. Modeling migratory flight in the spruce budworm: temperature contraints. Forest 2019. under review.

46. Régnière, J.; Garcia, M.; Saint-Amant, R. Modeling migratory flight in the spruce budworm: circadian rhythm. Forests 2019. under review.

47. Robert, L.E.; Sturtevant, B.R.; Cooke, B.J.; James, P.M.A.; Fortin, M.J.; Townsend, P.A.; Wolker, P.T.; Kneeshaw, D. Landscape host abundance and configuration regulate periodic outbreak behavior in spruce budworm Choristoneura fumiferana. Ecography 2018, 40, 1-16. [CrossRef]

48. Gray, D.R. The relationship between climate and outbreak characteristics of the spruce budworm in eastern Canada. Clim. Chang. 2008, 87, 361-383, Erratum in 2008, 89, 447-449. [CrossRef]

49. Royama, T. Analytical Population Dynamics; Chapman Hall. N.Y.: New York, NY, USA, 1992; p. 371.

50. Fleming, R.A.; Barclay, H.J.; Candau, J.N. Scaling-up an autoregressive time-series model (of spruce budworm population dynamics) changes its qualitative behavior. 2002. Ecol. Model. 2002, 149, 127-142. [CrossRef]

51. Blais, J.R. Trends in the frequency, extent, and severity of spruce budworm outbreaks in eastern Canada. Can. J. For. Res. 1983, 13, 539-547. [CrossRef]

52. Royama, T. Moran effect on non-linear population processes. Ecol. Monogr. 2005, 75, 227-293. [CrossRef]

53. Abbott, K.C. Does the pattern of population synchrony through space reveal if the Moran effect is acting? Oikos 2007, 116, 903-912. [CrossRef]

54. Hugueny, B. Spatial synchrony in population fluctuations: extending the Moran theorem to cope with spatially heterogeneous dynamics. Oikos 2006, 115, 3-14. [CrossRef]

55. Liebhold, A.M.; Johnson, D.M.; Bjornstad, O.N. Geographic variation in density-dependent dynamics impacts the synchronizing effect of dispersal and regional stochasticity. Popul. Ecol. 2006, 48, 131-138. [CrossRef]

56. Vasseur, D.A. Environmental colour intensifies the Moran effect when population dynamics as spatially heterogeneous. Oikos 2007, 116, 1726-1736. [CrossRef] 
57. Denno, R.F.; Peterson, M.A. Density-dependent dispersal and its consequences for population dynamics. In Population Dyanmics: New Approaches and Synthesis; Cappucino, N., Price, P.W., Eds.; Academic Press: New York, NY, USA, 1995; pp. 113-130. ISBN 0-12-159270-7.

58. Silva, J.A.L.; Giordani, F.T. Density-dependent migration and synchronism in metapopulations. Bull. Math. Biol. 2006, 68, 451-466. [CrossRef] [PubMed]

(C) 2019 by the authors. Licensee MDPI, Basel, Switzerland. This article is an open access article distributed under the terms and conditions of the Creative Commons Attribution (CC BY) license (http://creativecommons.org/licenses/by/4.0/). 